\title{
Problems of digitalization of the educational process in the system of secondary vocational education
}

\author{
Elena Khitrova* \\ Baikal State University, 664003 Irkutsk, Russia
}

\begin{abstract}
Modern requirements for the training of specialists in the system of secondary vocational education involve the active use of digital technologies. A future college graduate must have the appropriate competencies that will allow him to be competitive in the labor market, be able to adapt to the requirements of the profession, and navigate the flow of changing information. The article shows the need to take into account the features of the system of secondary vocational education, these features are considered. Identified the risks associated with digitalization and their impact on the quality of education in the secondary vocational education system.
\end{abstract}

\section{Introduction}

In the context of new external challenges, the development of the secondary vocational education system began to occupy a significant place in development programs at the level of the state, regional authorities, and the educational community. Training of mid-level specialists is conditioned by social, economic, scientific, technical and educational characteristics and trends of changes in the external socio-economic environment and modern society in the Russian Federation and the world. The purpose of such training is to meet the needs of the economy and society as a whole in specialists capable of solving the urgent problems facing the economy of the region and the state as a whole.

The system of training middle-level personnel cannot be considered in isolation, therefore, the assessment of such indicators of economic development of any region as production volumes, real incomes of the population, consumer demand, financial stability of the budget, the inflow of investments have a significant impact on the need for labor resources $[1,2]$.

Every year the number of students receiving education in institutions of secondary vocational education (SVE) is increasing for a number of objective reasons. From the standpoint of the state, this is a positive trend, since there has long been a need to restore the lost quality of carriers of knowledge and competencies in working specialties that are in demand in the real economy [3].

The main task of the state policy in the field of secondary vocational education in accordance with the profile law of the Russian Federation "On Education" is to increase the

\footnotetext{
* Corresponding author: HitrovaEM@bgu.ru
} 
level of a set of competencies and the quality of a special type of education received in this segment of the general educational system of the country, as well as a general increase in the importance and prestige of obtaining secondary vocational education that meets modern the needs of our country.

In turn, the main indicator of the efficiency and effectiveness of the SVE system is currently the quality and demand for graduates[4]. In modern society, the requirements for the level of professional training of students, the goals, content and technologies of professional education of students in vocational schools of any direction and profile of training have significantly increased.

All this necessitates the improvement of the existing traditional methods of training students of secondary vocational education, using modern techniques and tools of education.

In the context of the development of the global information society, the building of the information society in Russia, the automation and informatization of the processes of providing state and municipal services, the dynamic application of information technologies in the economic system of each regional entity increases the relevance of the use of information technologies in the educational process of any level.

\section{Research methodology}

The study of the role of digitalization of the educational process in the SVE system predetermined the need to identify the features of training mid-level personnel. There are differences from other education systems that need to be taken into account when introducing digital technologies into educational content. As a research method, we used the analysis and synthesis of information obtained by questioning a sample of respondents that meet the requirements of representativeness in terms of volume and structure. The analysis of the practical experience of the author of the article made it possible to give an expert assessment of the instrumental content of information technologies used in the educational process in the SPE system.

\section{Results}

Much attention is paid to the digitalization of the educational process at all levels of training. However, the training of mid-level specialists and the conditions for using digital technologies for their training have a number of peculiarities.

About $85 \%$ of all students in the secondary vocational education system are young people aged 15-17 who study in vocational education programs after receiving a diploma in basic general education. Already in the first year of study, the content of education includes subjects of both school and professional programs, which provides for the use of digital technologies in the educational process. This age is characterized by a propensity for digital addiction, difficulties with planning and time management. Therefore, the main work of the teaching staff is aimed at achieving students' understanding of their educational needs, increasing their own learning motivation and developing cognitive independence.

Trends in recent years point to the growing role of training mid-level specialists in the development of the country's economy. The state is interested in teaching students who are able to use modern technologies and implement the development of scientific and technological progress. This imposes certain requirements on the educational process in the vocational education system. Their essence lies in the use of practice-oriented learning in the educational process. Changes in educational standards in recent years consist in strengthening the requirements for the material and technical base. This means that educational institutions should have workshops and laboratories in which future professional 
activities are simulated. The curriculum contains a large number of practice hours, which can be organized by alternating with theoretical sessions in the training of the professional module. The number of hours devoted to the variable part can not only strengthen or supplement theoretical disciplines, but also be used for practical training. In addition, one professional module is necessarily associated with the development of a working profession or employee position [5].

As part of a sociological study, students were asked about the problems of vocational education through the eyes of students. The answers were distributed as follows: $11 \%$ note a low level of interaction with the employer and the impossibility of choosing an individual trajectory, $13 \%$ a weak material and technical base, $10 \%$ low involvement in practical activities.

Russia's entry into the world movement Worldskills made it necessary for students to master professional competencies that are as close to work as possible. For this, practiceoriented forms of final certification of graduates are provided - a demonstration exam according to Worldskills standards, an independent assessment of the quality of graduate training, and inviting potential employers as experts. Centers of professional competence are being created, equipped in accordance with the WorldSkills infrastructure lists, on the basis of which practical training is carried out, advanced training of teachers and masters of industrial training is organized [6].

All this makes new demands on the educational process from the point of view of the willingness of the teaching staff to simulate the necessary skills when conducting classes. And here, the use of information technology in terms of special software allows you to develop the necessary skills for further use in production. Those. digitalization acts as a kind of tool for practicing the acquired knowledge in practice [7].

Another feature of personnel training in the vocational education system is the need to take into account the needs of a particular territory in a certain kind of mid-level specialists.

Regional authorities should regulate the composition of the formed professional competencies of graduates. And the list of optional disciplines should be determined by the educational organization taking into account the specifics of the regional labor market. Accordingly, the digital technologies being introduced must also meet the requirements of the regional labor market, contribute to the formation of demanded competencies. [8]

These features give rise to a number of problems associated with the implementation of digital technologies in open source software. First of all, this is the unpreparedness of a significant part of the teaching staff for the total implementation of educational digital technologies in their classes. And there are explainable reasons for this. The level of wages and scholarships in the middle management leaves much to be desired. This is the main brake on the motivation of teams for innovative development and modernization of the educational process. The quality of human resources, the level of scientific support and the share of scientific research working on the development of the system are growing, and sometimes remain at the same level, at a slower pace than is needed today. Lack of interest among potential young teachers to work in the SVE system leads to an increase in the average age of the teaching staff. The work intensity is very high. The weekly workload according to the curriculum is 36 hours per week. In the structure of the load, from 70 to $100 \%$ is the classroom load. The volume of the annual load averages 1440 hours. In recent years, when the number of SVE students is growing, this has led to an increase in the workload per teacher. Considering that the average age of teachers is over 50 years old, this becomes a serious problem of the quality of training. Age teachers, for obvious reasons, experience certain difficulties in introducing information technologies into the educational process.

The quality of education is considered by researchers of this concept not only as the quality of education, depending on the level of teaching [9]. Many people understand the quality of education as the degree of personality development, the graduate's readiness for 
professional activity, the ability to critically assess information, reflect, and formulate their own opinion [4]. Therefore, the introduction of digital technologies in the implementation of educational programs also has a number of risks that reduce the quality of training: the ability of students to perceive and process information, the emergence of digital addiction. This entails a departure from the fundamental nature of education, a decrease in the creative component of learning, that is, the loss of basic cognitive competencies. Avoiding fundamentality, the emergence of problems of the formation of practical skills, the readiness of graduates for effective oral business communications, a decrease in the motivation of direct communication and work in a team, finally, physical development disorders (decreased vision, physical activity, disorders of the musculoskeletal system), provoking students to cheat and avoiding assignments (for example, guessing the answers in a test) are all negative aspects of indiscriminate digitalization in learning.

Finally, one cannot fail to note the challenges posed by the presence of external threats. The situation of the last year, when training was carried out in a distance format due to the COVID-19 pandemic, exacerbated the problems associated with the use of digital technologies in terms of the quality of education [10,11]. The study, carried out by questioning 600 students of secondary vocational education, showed mixed results. According to the survey, the overwhelming majority (79\%) noted that the number of classes did not change. The analysis of the situation really showed that educational institutions of secondary vocational education in a short time were able to organize the educational process using distance information technologies. However, 29\% note that the quality of education has deteriorated. The reasons for the decline in the quality of education are clear. These are difficulties with the material and technical base of educational institutions, difficulties in mastering new formats of education by teachers, a significant increase in the independent training of students.

At the same time, the distance learning format has its advantages. $41 \%$ of students noted the availability of education from any place, $11 \%$ noted an individual approach to learning and focus on educational needs. The disadvantages of the remote format $13 \%$ refer to the difficulty of communication with the teacher, $21 \%$ noted the difficulty in mastering the material and $27 \%$ the presence of technical problems with the connection. $19 \%$ lacked live communication with classmates and teachers.

The solution of these problems and the prevention of risks can be facilitated by the integration of digital technologies with effective traditional technologies, which will enhance their didactic effect and, ultimately, the quality of graduate training.

\section{References}

1. V. Samarukha, T. Krasnova, T. Plotnikova, Bulletin of the Baikal State University, 29(3), 476 (2019)

2. S. Ovanesyan, A. Sukhodolov, A. Rasputina, TIES 2020 International conference «Trends and innovations in economic studies» Social and Behavioural Sciences EpSBS, 474 (2020)

3. K. Shulyako, IX All-Russian scientific-practical conference, 121 (2020)

4. T. Shestakova, V. Bozhinova, Education. The science. Innovation: Southern Dimension 3-4(45), 18 (2017)

5. E. Protas, Y. Sharonin, Law and Education 6, 42 (2007)

6. M. Maznichenko, D. Lopatinsky, Professional education in Russia and abroad 3(39), 35 (2020)

7. A. Atanov, E. Zimina, Transformation of the social world in the modern era, 34 (2019) 
8. A.Webb, M.William, R. William, World journal of science technology and susnainable development 1, 18 (2021)

9. F. Saidova, Development of scientific concepts "quality", "quality of education", "quality management of education", World Sience: Problem and innovation, 309 (2016)

10. T. Poddubnaya, E. Zadneprovskaya, S. Voevodina, Distance Learning Experience in Context of Globalization of Educftion 9, 985 (2021)

11. S. Bulganina, M.Prokhorova, T. Lebedeva, Digital skills as a response to the challngen of modern society, Turismo-estudos e practicas (2021) 